\section{The Organic Farming Movement in Europe}

\author{
Silviero Sansavini ${ }^{1}$ and \\ Joerg Wollesen ${ }^{2}$
}

Additional index words. history, regulation, organizations, systems, research

\section{Introduction}

Organic farming is a topic of marked interest in Europe today. The term "organic farming" is currently used to indicate those methods of crop and livestock production that seek to reduce outside energy inputs (some proponents would even include modern technology) as much as possible and to eliminate synthetic chemicals from the agricultural ecosystems. The aim is to reestablish an integral bond of agriculture with nature. The roots of the organic movement are ancient (see R.F. Korcak's paper in this Workshop), but the current reformulation is traceable to events initiated in Europe during the first half of the 20th century. These include the principles of biodynamics as embodied in the Anthroposophical Society founded by Rudolf Steiner of Austria in 1912, which currently operates through an international foundation called "Demeter"; biological farming (based on organic and microbiological concepts) propounded by Müller and Rusch of Switzerland in the 1950s; the importance of organic compost and lime-rich algae put forth by the Lemaire and Boucher of France; green manure, polyspecies pasturage, and crop rotation advocated by Howard and Balfour of England in the 1940s; and the role of organic composts championed by Draghetti of Italy in the 1950s.

These ideas have enjoyed a resurgence since the 1970s and have spawned several active movements attracting a limited but enthusiastic and tenacious group of adherents. Yet, with the exception of biodynamic agriculture, the movement's various strands tend in effect to converge about the common denominator of "organic/biological farming"-the result of a process of regulatory uniformity that also is driven by market forces.

'Istituto di Coltivazioni Arboree, Univ. of Bologna, 40126 Bologna, Italy.

${ }^{2}$ Villa Belvedere, 2505 Desenzano (Bs), Italy.
The International Federation of Organic Agriculture Movements (IFOAM), founded in 1972, is the main international umbrella organization and includes most of the organic-oriented grower, processor, and marketing associations as well as research and consumer-advocate groups. A "Continental Section" of the IFOAM has recently been established in Europe; it features several subsections covering large regional areas such as the Mediterranean. The IFOAM is proving to be an essential instrument for disseminating reliable information and developing a common "naturalorganic" approach to agricultural and environmental issues.

The objective of this survey is neither to catalog organic farming techniques nor debate the experimental basis for the moment, but rather to provide an overview of the present position of the organic movement in Europe as it relates to market-oriented organic farms managed under mainstream economic criteria.

\section{Development of organic farming in Europe}

A rough idea of the increasing importance of organic farming can be gleaned from estimates made from the few data collected by scholars (especially Lampkin, 1990; see Table 1). They show that the average organic-crop area in the European Community (EC) as compared with total crop area ranges from $0.1 \%$ in Spain and Portugal to $0.4 \%$ in Germany and the Netherlands to $0.6 \%$ in Denmark. Slightly more than 10,000 farms are involved overall, or a total of $\approx 200,000$ ha. These figures are certainly not high in absolute terms, but neither are they negligible, considering the strong motivating forces and the determination of the practitioners and the interest they have generated in consumers, who are increasingly attracted to the concept of "organic."

It should be stressed that the development of organic farming can be seen as a spontaneous phenomenon linked to "crop reconversions" that growers have gradually undertaken almost without government subsidies. Still, only a few European countries have enacted specific legislation regarding organic farming: France (since 1980) Austria, Denmark, Italy (regional only), and, to a certain extent, Spain, Norway, Finland, and the United Kingdom. These measures include crop standards, regulatory agencies and certification schemes, provisions for economic incentives, and the promotion or creation of specific extension services.

In deciding whether to embrace certain tenets of organic farming, ethical and emotional factors that strongly color the attitudes of growers and consumers are often considered before proven technical reports and positive economic performance. Some growers are willing to risk part of their crop and profits (not to mention professional reputation) in the conviction that they are fulfilling a social and cultural obligation. This accords with a conservation and ecological view that looks on agriculture as a restorer and steward of natural resources, coincident with a reduced dependency on technology. The view is that the production cycle of a farm should become, as far as possible, a "closed circuit" to recycle and reemploy the maximum amounts of organic elements, biomass, and waste products generated by livestock and crop operations.

For their part, consumers are captivatingly attached to a rustic and romantic concept of agriculture and rural areas. They tend to imbue an ideal agriculture with the principles of organic farming and attribute, by association, genuineness and healthfulness to "organic" produce. Organic producers in certain sectors have reaped benefits in terms of market niches they have carved for themselves, as shown by the distribution networks and hundreds of organic (mainly or only) retail outlets that have sprung up in the more developed European countries. In addition, the organic movement is associated with positive effects on consumer dietary habits typified by a reduced intake of calories, processed foods, red meat, and animal fat and an increase in fruits and vegetables. Yet, while the introduction of organic foods by certain large supermarket chains (e.g., IRMA in Denmark and Safeway in the United Kingdom) has promoted their sales to the mainstream consumer, other chains have encountered problems.

The prices consumers are willing to pay for these products, even without credible, certified labels, average $\approx 30 \%$ over the standard (although $50 \%$ to $100 \%$ for certain products is not uncommon), a difference that is especially notable in such sectors as dairy, cereals and legumes, vegetables, and, to a much lesser extent, fruits. The few reliable surveys published so far suggest that production costs are higher in terms of labor but lower in terms of technological input, with the overall unit-cost usually being higher because of a drop in per-unit yields compared with conventional agriculture (when the latter's goal is to maximize output).

\section{Organic farming in Europe}

Individual European countries have displayed a variety of responses to the challenge of organic farming.

\section{Belgium}

The Belgian situation is complex. It is dominated by the ASBL-Biogarantie, the umbrella organization charged with granting trademarks to member companies, As of 1990 there were four established groups: UNAB-Nubila, Probila-Unitiab, Nature et Progres, and Velt. There is still no specific legislation except for an "Arret Royal" regulating the advertising of organically grown products. 
Table 1. Organic farming in Europe.

\begin{tabular}{|c|c|c|c|c|c|c|}
\hline \multirow[b]{2}{*}{ Country } & \multicolumn{2}{|c|}{ Farms (no.) } & \multicolumn{2}{|c|}{ Area (ha) } & \multicolumn{2}{|c|}{ Percentage of total area } \\
\hline & 1987 & 1990 & 1987 & 1990 & 1987 & 1990 \\
\hline \multicolumn{7}{|l|}{ EC } \\
\hline Belgium & 103 & 150 & 972 & 1,200 & 0.09 & 0.16 \\
\hline Denmark & 253 & 520 & 4,000 & 15,500 & 0.55 & 0.60 \\
\hline France & 2,660 & $3-4,000$ & 40,000 & $40-60,000^{y}$ & $0.13-0.20$ & $0.3-0.4$ \\
\hline Germany & 1,930 & 2,685 & 35,400 & 54,295 & 0.46 & 0.38 \\
\hline United Kingdom & 618 & 700 & 8,619 & 16,000 & 0.09 & 0.27 \\
\hline Ireland & 37 & 150 & 1,300 & 3,700 & 0.06 & 0.07 \\
\hline Italy & 986 & $N A^{x}$ & 6,000 & NA & 0.03 & 0.04 \\
\hline Luxemborg & 13 & 14 & 412 & 550 & 0.43 & 0.35 \\
\hline Netherlands & 478 & 440 & 3,384 & 7,600 & 0.38 & 0.32 \\
\hline Portugal & 7 & 61 & 185 & 550 & 0.01 & 0.01 \\
\hline Spain & 328 & $500-1,000$ & 2,700 & 5,500 & 0.02 & 0.06 \\
\hline \multicolumn{7}{|l|}{ Non-EC } \\
\hline Austria & $>700$ & 1,250 & $>10,000$ & 22,500 & & \\
\hline Finland & $<335$ & 850 & $<2,050$ & 11,000 & & \\
\hline Sweden & 500 & 1,900 & 7,500 & 29,000 & & \\
\hline Switzerland & $>1,010$ & NA & $>11,800$ & NA & & \\
\hline
\end{tabular}

Source: Okologie-Landbau, 78, 1991. p. 55.

"Probably overestimated.

Data not available.

\section{Denmark}

The country's first legislative measure concerning "ecological agriculture" was enacted in 1987 and included the establishment of a Council for Ecological Agriculture. The act makes provisions for product identification, a national regulatory agency, subsidies for farm conversion (1500 to $2200 \mathrm{DKr} / \mathrm{ha}$ the first year, 800 to 1180 the second, and 300 to 420 the third), and research funding.

\section{France}

Act 80/502, dated 7 Apr. 1980, represents the first law enacted by a European country on organic farming, defined simply as "agriculture without the use of synthetic chemicals." Its provisions include financial assistanceand a national regulatory commission to oversee the adoption and enforcement of production or processing standards through an association acting as guarantor. To date, 14 such intermediary associations have been established, each with its own specific regional or national regulatory code: the $\mathrm{ABF}$, ANAAB, CINAB, COMAC, EAP, FESA, FNAB, FNDCB, GGPAB, SIMPLES, SNAS, SOCOTEC, UNIA, UNITRAB. Worthy of note in this connection is the establishment of the ACAB, a national extension association, which in turn founded ECOCERT, a certification board for organic products The board, which acts on applications received, currently boasts a clientele of $>2500$ growers and 300 marketing firms or information services. It has not been easy overcoming the diffident stance of French consumers vis-à-vis socalled organic products.

The demanding nature of the French market can be seen in the press exposes of fraud involving produce grown with chemical fertilizers or treated with pesticides, yet marketed under the Ministry of Agriculture's official AB ("organic farming") logo. Since Dec. 1988 the Ministry has attempted to remedy this situation by making it compulsory for all organic farmers to join one of the officially approved associations. Despite this measure, and the fact that infractions of the law carry fines as high as 250,000 francs and prison terms up to 2 years, the problem has not been fully eradicated, and the sanctioning power of some associations may be revoked. Indeed, new local oversight agencies, like COMAC, are being set up regionally to monitor growers and processors. These issues underscore the fact that the French system is an honor system requiring self-discipline from all members of the regulatory associations involved in the organic pipeline.

The first organic fruit plantations in the southern part of the country have limited production at the moment (e.g., barely 100 t.year ${ }^{-1}$ in the Gard, $200 t$ in the eastern Pyrenees). They emphasize apricot, cherry, peach, plum, strawberry, table grape, and kiwifruit. The most important monitoring bodies are Nature et Progres, Terre et Vie, Biofranc, Bioplampac, France Nature, UNIA, and Demeter. There are many special wholesale and retail operations. A privately funded organic farming research group called Groupe de Recherche en Agriculture Biologique (GRAB) has recently been formed, and it co-organized a workshop on organic agriculture with ACAB (ACAB-GRAB, 1990).

\section{Germany}

In Germany, there are eight oversight agencies that monitor the organic farming activities and practices of their members. Regulatory policies are now being extended to processing and marketing. The list of agencies (Table 2) includes Demeter (biodynamic farming), a rather complex umbrella organization covering various operational groups: Bioland (organic farming), Biokreis (organic group of eastern Bavaria), Naturland (natural farming), ANOG (Movement for Natural Growing of Horticultural Crops), and BOW (National Federation of Ecological Viticulture). These six groups in turn make up AGOL, the Consortium for Ecological Agriculture established in 1988, to which two recently founded associations, Neukoba (certified organic farming), and Bola (a federation for ecological agriculture) have applied for membership. Each of these eight groups has its own logo that also serves as a trademark.

The members of these associations are required to observe a regulatory code or specific guidelines concerning production, processing, or distribution depending on the type of organization. For its part, the association which charges a small percentage of billings as a membership fee, provides extension or consulting services, market oversight and product promotion, and consumer information. It also conducts one or two field inspections yearly and can decide whether to carry out further investigations, for example by commissioning private laboratories to run tests. If the findings are negative, the association issues a statement that is not a quality warranty but that certifies only that the produce meets organicprocedurecriteria. The IFOAM reserves the right to check that organic procedures are in compliance via a special monitoring panel. The German government plays no oversight role, at least as long as national legislation is not enacted to impose mandatory standards. 
Table 2. Organization of the organic farming movement in Germany.

\begin{tabular}{lcccl}
\hline Agency & $\begin{array}{c}\text { Year } \\
\text { established }\end{array}$ & $\begin{array}{c}\text { Farms } \\
\text { (no.) }\end{array}$ & $\begin{array}{c}\text { Area } \\
\text { (ha) }\end{array}$ & $\begin{array}{c}\text { Cropping } \\
\text { system }\end{array}$ \\
\hline Demeter (Biodyn) & 1924 & 1,098 & 23,914 & Organic-dynamic \\
Bioland & 1971 & 1,623 & 36,343 & Organic \\
Biokreis & 1979 & 150 & 2,151 & Bavaria-organic \\
Naturland & 1982 & 401 & 10,830 & Natural soil \\
ANOG & 1962 & 78 & 2,009 & ANOG \\
Ecovin & 1985 & 76 & 285 & BOW \\
Neukoba & 1988 & $?$ & $?$ & Organic control \\
Bola & 1988 & $?$ & $?$ & Ecological
\end{tabular}

זThese agencies are coordinated by the AGOL Federation located at the Darmstadt Research Inst. (Source: Okologie-Landbau 78, 1991, p. 55).

Each of these associations has its own management charter. For example, Demeter is a multifaceted organization and includes the Darmstad Agro-Biodynamic Inst. Its board of directors includes representatives from several independent bodies or concerns that play a key role in formulating group policy, production flow, and planning such services as research and consulting, regulatory codes and contracts to safeguard production, product quality standards, processing, distribution and retailing guidelines, and consumer relations and advertising. Members pay fees ranging from $1 \%$ to $3 \%$ of their billings and are free to set their own prices and to sell to whomever they wish. Demeter certifies the produce of its members, legally safeguards their rights, prevents fraud, and conducts field inspection and laboratory testing. It should be noted that in the first few years of a farm's conversion to organic techniques, the Biodyn trademark replaces Demeter's.

Two other private concerns-Okosiegel ("Ecoseal") and Biocontrol System-also offer inspection and certification services to those farms that do not belong to any of the eight associations mentioned above.

Germany's entire organizational setup needs to be sanctioned by national legislation. As with Italy, this probably will come about as soon as the EC enacts its own measures, but there are many political hurdles still to be overcome.

Events appear to be outstripping intentions. At least $50 \%$ of Germany's organic produce market is completely unregulated. The lack of nationwide regulatory provisions has enabled imported, generally uncertified organic products to penetrate German markets. Nevertheless, the entire market enjoys benefits from the success of the officially approved products. The fact that organic farming is stressing overall quality suggests that present quality levels are unsatisfactory, especially in regard to small-scale processing products, such as juices.

There are currently $>2000$ retail outlets (Naturkostläden). The opening announcement of the largest "ecological" supermarket at Gerestried, Munich, noted that most of its 2500 items were foods and that projected first-year sales should reach $\approx 2$ million DM. The Federal Environmental Agency recently awarded AGOL funding for a research and consultancy project entitled "Development and Testing of a Marketing Program for Ecologically Grown Products and Foods for the General Public: Canteens and Restaurants." The European Research Institute for Biodynamic Farming, headquartered at Darmstadt, has been conducting organic-farming research for at least a decade; research is also ongoing in university departments and experimental stations at Bonn, Giessen, Kiel, Kassel, Witzenhausen, and Triesdorf (Table 3).

\section{United Kingdom}

The United Kingdom boasts a certain tradition in the field of organicagriculture that includes several research centers. The main ones are the Elm Farm Research Station at Hampstead Marshall in Berkshire, where a very interesting project is underway on stockless arable rotations, and the Aberystwyth Centre for Organic Livestock and
${ }^{2}$ Seminars and laboratory not included.
Agroecology, directed by N. Lamkin at the Univ. of Wales, which is primarily concerned with economic research and consultancy. The Soil Assn., which wasestablished in 1948 by Lady Eve Balfour in the wake of Howard and Balfour's organic theories, still plays a key role in research and also issues a trademark for organic food products. The U.K. government has set up a body to supervise standards, inspection procedures, and labeling as a consumer protection measure.

\section{Italy}

Italy still has no national legislation, despite the many bills drafted either separately or together by the various political parties or by the Ministry of Agriculture in 1990. Legislation is stalled in parliament awaiting the EC guideline measure. Meanwhile, however, laws on organic farming have been passed by the more active of the regional governments (the Lazio, Veneto, Friuli, TrentinoAlto Adige, Marches, and Umbria regions). Although most of these measures have remained largely on paper for lack of enforcement regulations, their provisions call for official recognition of organic growing techniques, incentives, and subsidies for farm conversion (e.g., 200,000 lire/ ha in Emilia-Romagna and 300,000 lire/ha in the Marches for green-manuring) and a (promised!) extension service.

Growers have responded to this public-sector inertia with various initiatives. They have established a number of regional cooperatives and associations committed to observing the IFOAM standards and to marketing organic-labeled produce either directly or through affiliated retail outlets. Of a total of $\approx 10,000$ ha of organic crops, 3000 ha are under conversion and 1500 under biodynamic farming, and some regional authorities have made a few extension service agents

Table 3. University courses in organic agriculture in Europe.

\begin{tabular}{llcl}
\hline Country & \multicolumn{1}{c}{ Town } & Hours (no.) & \multicolumn{1}{c}{ Subject } \\
\hline Austria & Innsbruck & $?$ & Agro-ecology \\
& Vienna & 26 & Animal organic farming \\
Belgium & Gembloux & 52 & Biological agriculture \\
Denmark & Frederiksberg & 26 & Alternative agriculture \\
Germany & F. Wilhelm Univ. & $?$ & Intro to organic agriculture \\
& Giessen & 26 & Technique and conventional agriculture \\
& Kiel & 26 & alternatives \\
& Nurtingen & 26 & Crops in organic agriculture \\
& Hohenheim & 26 & Yiternative methods \\
& Hohenheim & 13 & Alternative agriculture for animals \\
& Hohenheim & 13 & Marketing of organic crops \\
& Hohenheim & 13 & Economy in alternative agriculture \\
& Hohenheim & 13 & Special crops in alternative agriculture \\
& Munich & & \\
(Weihenstephan) & $13 \times 4$ & Alternative agriculture \\
& Witsenhausen & 26 & Introduction to alternative agriculture \\
& Witsenhausen & 26 & Agriculture and ecology \\
\hline
\end{tabular}


available in the field and for laboratory analyses. Most of these groups are part of the AIAB (the Italian Organic Farming Assn.), a prevalently grower-oriented organization, which began issuing in 1991 an organic procedure warranty ("Garanzia AIAB"). Another association now being established with a code of standards along the lines of IFOAM (tests included) is the Interprofessional Federation for Organic and Biodynamic Agriculture (FIABB), which will open membership to the processing industry, marketing firms, extension agents, retailers, and consumers as well as growers. Its agenda is ambitious: to represent all the sectors of the organic-product industry at national and international levels; to become the main policy and legislative lobby; to promote and advertise organic products; to set up joint programs with public research agencies and bureaus of standards; and, of course, to monitor affiliates and check regulatory and certification systems.

The monitoring of organic produce in Italy has received a boost from 25 large cooperatives that have joined in establishing an oversight consortium. Currently, only 1000 out of an earmarked 25,000 total hectares comes under the definition of "organic."

The Italian market has a nationwide network of $>400$ retail outlets for organic products from a wide variety of sources, many of which have unverified warrantiesand partly documented labels. The main items are cereals (wheat, rice, corn, and such minor species as millet), some soybean, milk and yogurt, fruits, including citrus and juices, vegetables, oil, and wine. Despite the rather high prices organics command, the industry foresees a rapid expansion for organic products. Problems, however, are anticipated: with $\mathrm{N}$ (probably the primary one in Italy, as in many other countries), for it is closely linked with organic livestock, with dairy and horticultural production, and with "organic" fruit due to the ban on certain chemicals considered essential for fruit production (Tringale, 1990).

\section{The Netherlands}

The Dutch Platform for Biological Agriculture, the government-recognized lobby and consultant for public research programs, is the umbrella federation for the biodynamic and ecological agriculture sectors, each of which numbers $\approx 200$ growers, as well as such "nature" groups as the Small Earth Foundation, the Alternative Consumers Assn., and a few conservation and environmental organizations. There is no national legislation. There is, however, what may be Europe's longest-running comparative experiment of model farms at Nagele. The number of retail outlets for organic products now stands at $>300$, about 50 of which are also health-food shops, The main trademarks are Demeter-Biodyn and Eco. It bears reiteration that the country's leading supermarket chain, Albert Heijn, has decided to promote integrated rather than organic foods,
The Dept. of Ecological Agriculture was established at Wageningen in 1981. It has the only program in Europe offering an undergraduate degree and a postgraduate MS.

\section{Spain}

National legislation was enacted on $10 \mathrm{Apr}$. 1989 to regulate "ecological farming." Its provisions include the establishment of an oversight board to draft the regulatory codes of production, an official registry of affiliated growers, the monitoring methods approved by the Ministry of Agriculture to be used by the board in managing the service, and, in the future, a trademark for organic produce. "Vida Sana" is the country's dominant organic organization; nearly half the certified organic area in Spain is in olive groves, and much of the remainder is either citrus or intensive vegetables for export.

\section{Switzerland}

Switzerland has a certain propensity for organic farming, in that far less of its agriculture has been involved in today's dominant intensive and monoculture approaches than is true for othercountries. Currently, there are at leastseven large associations in addition to the Oberwil Research Institute for Organic Farming, one of the most important organic research organizations in Europe. The institute, which also includes individual growers, has four departments: soil and fertilization, plant protection and landscape ecology, socio-economic projects, and education service. Much of the historical merit for the development of organic farming goes to Müller, who established the first nucleus of organic farmers in the 1950s.

Today, growers are represented by VSBLO, the Swiss Federation of Organic Farming Movements (Demeter, Italian Switzerland's AB, Biofarm, Biogermuse AVG, Progana, SGBL, Swiss Foundation for the Promotion of Organic Farming), whose $\log _{0}$ is a bud. Despite the rigorous production regulations established by VSBLO, there is as yet no national legislation covering organic farming, although several cantons, such as Basel and Bern, have passed measures providing incentives for organic growing and farm conversion. These subsidies include $\approx 2000$ Swiss francs per farm for training, a similar sum for equipment purchasing, and a small amount more for conversion. Worthy of note is the fact that as of 1991 (i.e., 10 years after conversion) ethological norms will become part of farm management practices for livestock operations: intensive breeding methods in cages (e.g., for chickens) are to be prohibited.

The market share of organic produce has risen steadily up to now: its reputation is good and fraud rare, and prices seem to be profitable despite the rather small amount of produce currently on the market. Yet the fact that the predominant Migros supermarket chain has begun offering a MigrosSano line of integrated rather than organic prod- ucts may signal, as we have noted, that organic farming and its produce are reaching a plateau in Switzerland, and that consumers are resistant to pay high prices for these products.

Also. noteworthy is the interaction of the various associations and public sector research and education institutions. Comparative testing of crops grown under the three DOC techniques (Demeter, Müller-Rusch, conventional) has been under way since 1972 at Oberwil's IRAB and will undoubtedly have political effects, but no conclusive data on the performance of organic and conventional crops have been released.

\section{Organic farming systems}

While it is impossible to examine all the systems of organic farming, they do have certain common features that can be traced through sector, species, or type of farm. The first is the tendency toward a-self-sufficient management of the ecosystem without outside energy inputs, and there are those who maintain that the energy balance should be managed by taking into account a given area rather than the individual farm. Similarly, it is necessary to determine real energy efficiency per output (not just per hectare of organic systems), including such inputs as cultivation for weed control, N-fixing crops, and the transporting and spreading of certain "natural" fertilizers and compost. Clearly, theecosystem isdisrupted wherever intensive farming systems exist (e.g., high-density fruit and vine production). Thus, it would be unfeasible to apply organic-farming models without first imposing a suitably long period of conversion and adaptation for integrated production programs. It will be important to convert to genetic material that is well-adapted to a given environment and contains intrinsic resistance to stress, diseases, and pests. These genotypes do not always exist.

Another feature is the recovery and/or conservation of soil fertility by promoting the reactivation of biological, biophysical, and biochemical processes (revising edaphic symbioses). It is, however, not possible to evaluate the recovery of fertility or balance of the ecosystem except over the long term (up to 20 years or more) and, hence, the emphasis is on reassessment of the soil's organic material and humus. This also bears upon those questions linking sustainable agriculture and soil fertility, which in turn should help to focus greater attention in the future on the rhizosphere, especially on root/mycorrhizal relationships and functions.

There is a need to consider the farm as a viable economic entity that is an integral part of its surrounding natural environment and to view the animals and plants, the soil and climate, and the "ecological infrastructure" (the landscape) as interdependent and inseparable parts of a whole. This is the reason that organic farming is associated with mixed cropping practices and that there is strong support for linking livestock with mixed 
grass and fruit crop systems. Organic farms are required to keep livestock when growing certain crops.

There is much support for interspecific groupings in orchard plantations, a system that has historically and economically been moving toward monoculture. The dominant concept for grasses (and with due reservations for fruit) is yearly rotation to prevent disorders deriving from soil sickness, fertility loss, and erosion; to reduce pest load and enhance the natural resupply of organic matter and $\mathrm{N}$; and to facilitate nutrient migration in soil layers.

Some groups advocate the closed-circuit farm, a management system independent of outside energy inputs. The concept is designed to increase active and long-lasting soil humus content by adapting crops and livestock operations as well as by limiting tillage to a minimum. Yet, obviously, the use of outside inputs is inevitable despite the desire to ban all synthetic chemical or readily soluble fertilizers. For example, livestock breeders are allowed to purchase feed within certain limits (a set percentage of overall requirements) so long as the number of head does not exceed given thresholds per unit of area. There are similar mandatory thresholds set for natural and organic fertilizers.

\section{Research Feedback}

There are as yet insufficient field trials, yield data, or economic information to assess objectively whether organic farming can succeed in the marketplace without the external input of subsidies. Yields of grasses and oil seeds generally diminish by $10 \%$ to $30 \%$ (20\% to $50 \%$ is the range in Germany) and are subject to severe losses, in the short term at least, whereas in orchard crops this gap can either disappear completely or markedly increase, depending on pest infestation, severity, and control. Uncontrolled attacks can wipe out profits, if not yields, altogether. In any event, higher prices to cover the almost inevitably greater incidence of per-unit product cost can beforeseen. Thus, it is also necessary to devise adequate costbenefit models for farms and to devise a uniform table of crop management techniques as reference standards.

Reinken's test data (1988) are instructive in this connection. The trials were designed to compare organic and conventional growing techniques for applesand were based on the input of $80 \mathrm{t}$ manure/ha, an excessive rate in any case. While the findings showed the economic viability of the organic approach, they also underscored its marked limits, including diminished fruit quality and greater incidence of scab. Vogtmann (1990) points out that it is not simply a matter of comparing the performance of the two approaches (for the organic can show unsatisfactory results in the short term) as much as of testing crop systems that call for low outside inputs.
A Swiss study (Besson et al., 1990) reported multiyear findings of comparative testing on conventional and DOC organic systems under a seven-crop rotation of grassesand eight regimes of organic fertilization. Their findings show increased biological activity in the organically dressed soils, yet the soluble nutrient contents decreased and the soil was very slow to attain balance under the organic regime. In Oberwil, Switzerland, Schmid (1990) reported an appreciable activity of Rumex obtusifolius in root extracts in trials involving 40 natural composts tested against fungal disorders in apple (even soybean lectin has proved to be active against scab). A number of studies on biological control of apple diseases using microorganisms are underway at Wadenswil.

\section{Conclusions}

In the wake of the undeniable progress achieved in the 1980s and the heightened interest of the European consumer (demand still appears to outstrip supply), organic farming appears to be on the verge of carving out a significant niche in overall agricultural production. The aim of the movements various groups is to surpass the $1 \%$ threshold soon and to reach a $2 \%$ to $3 \%$ quota of overall agricultural output over the next decade, although the more optimistic IFOAM target is an ambitious $10 \%$ by the year 2000 (Haest, 1989). The higher prices commanded and received in the marketplace encourage expansion. For their part, consumers (at least the elite who buy them) seem to be unconcerned about paying $10 \%$ to $30 \%$ more for them in their "conviction" (though unproven) that these products are safer and healthier than conventional produce (Brombacher and Hamm, 1990). There are more than a few consumers who mistake a certification of method for a quality warranty. It is clear that organic farming has a beneficial effect on consumption in that consumers can make a more individual, personalized choice over a greater range of options.

Yet, despite these positive aspects, there remain many questions and doubts that in part explain the delay in the EC's passage of regulatory legislation until 24 June 1991 . This measure, Regulation no. 2092/91, redresses the lacuna, although again only in part, as it covers organic crop production, including marketing rules, but not livestock (proposals for which will be submitted for decision in 1992). It is to be enacted in two stages: the member states will have 9 months from the official issuing date, 27 July 1991, to apply the prescribed controls on the produce of organic farmers, who in turn will have 12 months to adopt the rules for use of the "Organic Farming-EC Control Authority" label. Produce then can indicate organic farming as its growing method in trademarks and advertising. The statute also includes the approved list of produce and management techniques, exceptions being kept to a minimum. Farms have beengranted a period of at least 1 year (up to July 1994) to convert from conventional to organic farming, during which time their produce must declare in advertising that any such farm is in the conversion phase.

While the measure has been favorably received by the public, which views it as a safeguard against fraud, it has provoked more than a few critical voices from organic farming proponents. On the one hand they feel a bit trapped by the rather stringent (at least on paper) inspection rules, yet on the other hand theycomplain that the guidelines regarding crop production and management practices (save the explicit norms on fertilization) are still somewhat vague. It can be assumed that conflicts will arise.

There are still many ways to misrepresent and make fraudulent claims as to production methods, a situation that is especially true for foreign suppliers (e.g., Hungary and Israel have "bent" IFOAM standards to meet local contingencies). Organization and implementation of controls raise consumer prices. Should supply increase to the point where organic farming is no longer profitable, the question will be raised if it must be self-supporting or be subsidized with public funds. For the moment, public funding in the various countries involved has been limited to incentives for conversion, but not as yet to cover the higher production costs of organic farms. Should this occur, it would be detrimental to conventional agriculture, which for the foreseeable future must provide our main source of food.

Human resource development in terms of education and training in organic farming, lacking in many countries, should be pursued and supported with adequate funding, as should research and training of research personnel. A recent study by Van Mansvelt and Kolster (1990) shows that the Netherlands, Germany, and Switzerland have the most advanced educational opportunities, i.e., university degree programs (Table 3). Other countries, including Italy, have been reluctant to pursue such a policy. Large agencies have changed their attitudes as organic farming gradually sheds its ideological tenets in favor of scientific proof. The FAO recently held a SARD1991 conference on sustainable agriculture and rural development.

In the opening report at the FAD's Expert Consultation Meeting at Bern, Switzerland, Gejer (1990) recognized that organic farming is but a sector of sustainableagriculture, and lists a series of proposals and objectives that are identical, albeit markedly more emphatic, to those formulated by the OILB and ISHS in their joint 1989 manifesto on integrated agriculture. Those who maintain that in a few years' time organic farming will be merely a variation of integrated agriculture may be right after all. 


\section{Acknowledgements}

We thank Jules Janick and John Landell Mills for their constructive criticism and suggestions.

\section{Literature Cited}

ACAB-GRAB. 1990. Ates du colloque Journ es Techniques de l'agriculture biologique. Fruits et legumes. Avignon, 12-14 Dec. 1990.

Besson J.M., N. Maire, and H. Suter. 1990. Etudes comparatives en production vegetale, p. 49-64. In: J.M. Besson (ed.). Biological farming in Europe. REUR, Techn S. 12, FA0, Bern, Switzerland.

Brombacher, J. and U. Hamm. 1990. Expenses for nutrition with food from organic agriculture. Ecology \& Farming 1:13-16.

Gejer, B. 1990. Principlesand development of biological farming in Europe, p. 15-18. In: J.M. Besson (ed.). Biological farming in Europe. REUR, Techn S. 12, FA0, Bern, Switzerland.

Haest, C. 1989 Present situation of the trade in organic foods and future perspectives. Main problems and demand for services. IFOAM Intl. Conf. Trade in Organic Foods, Zurich.

Lampkin, N. 1990 Organic farming. Farming press book. Ipswich, U.K.

Reinken, G. 1988. Integrierter gärtnerischer PflanzenbauNatwendigkeit, Probleme, Folgen, Gartenbauwissenschaft 53(5):193-198.

Schmid, 0. 1990. The concept and development of organic fruit growing in Switzerland. Acta Hort. 285:8189.

Tringale, M. 1990. Il biologico nei paesi mediterranei: II panorama Italiano. Bioagricultura 1(4):4-5.

Van Mansvelt, J.O. and P. Kolster. 1990. Education and training in organic agriculture: 1) Present situation and polar aspects of educational content; 2) Methodological aspects of appropriated human resource development indications of their implications, p. 99-126. In: J.M. Besson (ed.). Biological farming in Europe. REUR, Techn S. 12, FA0, Bern, Switzerland.

Vogtmann, H. 1990. Research structure in biological farming: General view, justification, development, p. 4147. In: J.M. Besson (ed.). Biological farming in Europe. REUR, Techn S. 12, FA0, Bern, Switzerland.

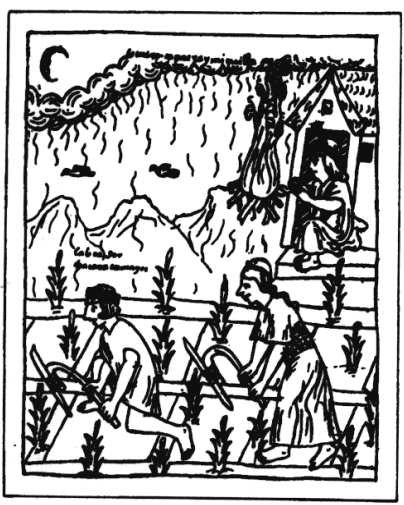

